\title{
ENTRE ROSAS E ESPINHOS, A AVALIAÇÃO E A EDUCAÇÃO A DISTÂNCIA
}

\author{
E.M.Dantas ${ }^{1,2}$, A.L. Troleis ${ }^{1,2}$ \\ ${ }^{1}$ Universidade Federal do Rio Grande do Norte \\ ${ }_{2}^{2}$ PPGEO - Universidade Federal do Rio Grande do Norte \\ eugeniadantas@yahoo.com.br, adrianotroleis@gmail.com
}

Artigo submetido em setembro/2012 e aceito em março/2013

\section{RESUMO}

Este artigo discute a avaliação como estratégia que favorece a compreensão do processo de ensino e aprendizagem. Enredada em contradições e incertezas, é um campo movente por onde circulam discursos e ações que visam medir e orientar a formação dos sujeitos. A Educação a Distância é mais um cenário que complexifica os desafios existentes, ampliando as possibilidades de discussão sobre autonomia, mediação pedagógica, professor, aluno em um contexto que requer a problematização sobre competências e habilidades, estratégias e programas. Como estratégia metodológica utilizou-se referenciais teóricos oriundos de autores como Pierre Lévy, Philippe Perrenoud, Edgar
Morin e Jussara Hoffmann, e a coleta de informações secundárias provenientes do ambiente virtual de aprendizagem (AVA). O uso do AVA e a reflexão teórica subsidiaram a análise sobre a avaliação e a aprendizagem, a partir das noções de competência e habilidade, programa e estratégia, permitindo concluir que: na Educação a Distância, a avaliação se constitui uma possibilidade para a construção de interfaces e diálogos entre os diferentes sujeitos, favorecendo a práxis docente na condução dos problemas relativos à aprendizagem, tornando-se um desafio perene no processo que envolve a formação.

PALAVRAS-CHAVE: Avaliação. Ensino a Distância. Competência. Habilidades. Estratégia.

\section{BETWEEN ROSES AND THORNS, THE EVALUATION AND THE DISTANCE EDUCATION}

\begin{abstract}
This article discusses the evaluation as strategy that promotes the understanding of teaching and learning process. Entangled in contradictions and uncertainties, this is a moving field where circle speeches and actions that aim to measure and guide the formation of subjects. Distance Education is another scenario that complexifies the existing challenges, expanding the possibilities for discussion about autonomy, pedagogical mediation, professor, student in a context that requires the problematization about competences and skills, strategies and programs. As methodological strategy were used theoretical references from authors as Pierre
\end{abstract}

Lévy, Philippe Perrenoud, Edgar Morin and Jussara Hoffmann, and the collection of secondary information derived from the virtual learning environment (VLE). The use of VLE and theoretical reflection subsidized the analysis about evaluation and learning, from the notions of competence and skill, program and strategy, allowing to conclude that: in Distance Education, evaluation is a possibility for the construction of interfaces and dialogues between different subjects, favoring teaching praxis in the conduction of learning problems, becoming itself a perennial challenge in the process that involves the formation.

KEY-WORDS: Evaluation. Distance Education. Competence. Skills. Strategy. 


\section{ENTRE ROSAS E ESPINHOS, A AVALIAÇÃO E A EDUCAÇÃO A DISTÂNCIA}

\section{INTRODUÇÃO}

Dentre os inúmeros problemas que persistem no cenário educacional, nesse início de século XXI, encontra-se a avaliação. Entrecortada por contradições e desafios, constitui-se num campo por onde circulam discursos e ações que visam medir e orientar a formação do homem, seja para o trabalho, para a competição, para a excelência, para a seleção, para a vida. No sistema brasileiro de educação proliferou, a partir da década de 1990, um conjunto de meios avaliativos que atinge desde o Ensino Fundamental até o Ensino Superior. Os objetivos são estabelecidos levando em consideração os resultados apontados por esse conjunto de avaliações, sendo um indicador importante para definir as perspectivas de curto, médio e longo prazos. Nesse contexto, as experiências pedagógicas assumem prerrogativas diversas, apresentando ideias e estratégias que se fragmentam no exercício cotidiano das ações educativas.

Dentre essas experiências incorporadas à práxis do século XXI, destaca-se o viés implementado pela Educação a Distância (EaD), que se apropria das tecnologias da informação para instaurar uma forma de saber-fazer, cuja matriz complexifica os desafios postos para a avaliação. A implementação de cursos, sejam eles voltados para o Ensino Médio, Superior ou em nível de Pós-Graduação, tem exigido a elaboração de um conjunto de mediações didático-pedagógicas que favorece a reflexão no processo de ensino-aprendizagem e que deve repercutir nas estratégias de avaliação, estejam estas vinculadas aos exames nacionais ou se apresentem como reféns das práticas que envolvem alunos e professores no exercício cotidiano das disciplinas, cumprindo as exigências da formação profissional.

De modo abrangente, pode-se afirmar que o Ensino a Distância está alicerçado na premissa de que a formação deve estar baseada na autonomia do sujeito aprendiz, que é estimulado a encontrar os caminhos que favoreçam o seu processo formativo, e do professor como coordenador e mediador de aprendizagens. Nesse sentido, objetiva-se discutir a avaliação como estratégia que favorece a compreensão do processo de ensino e aprendizagem, sendo a Educação a Distância um cenário que complexifica os desafios existentes quanto ao uso dos meios tecnológicos e às relações entre professor e aluno. A efetivação dessa reflexão passa, necessariamente, pela problematização que envolve a interface entre avaliação, competências e habilidades no processo formativo.

Desta feita, o percurso metodológico envolve referenciais teóricos oriundos de autores como Pierre Lévy, Philippe Perrenoud, Edgar Morin e Jussara Hoffmann, em que se discute a avaliação enredada em contradições e incertezas, um campo movente por onde circulam discursos e ações que visam medir e orientar a formação dos sujeitos nos diferentes momentos da vida e da escolarização, que é a medida da experiência, instituída como referência para a formação autônoma do sujeito. Nessa direção, a avaliação dos processos de ensino-aprendizagem no Ensino a Distância pode ser pensada a partir de noções como programa e estratégia. Esse campo conceitual foi associado ao ambiente virtual de aprendizagem (AVA) no que diz respeito às ferramentas e usos no processo de educativo, favorecendo a tessitura argumentativa de que a práxis docente se reveste de questões relativas à aprendizagem, na qual a avaliação é um desafio perene no processo que envolve a formação.

\section{A AVALIAÇÃO, DETERMINAÇÕES E INCERTEZAS}

Como uma questão que perpassa docência, avaliação é um campo fértil para emergências cognitivas o qual "inflama paixões", provoca a dor, desperta o prazer, estimula a mudança, cria resistência, modifica a práxis e revela os limites da condição que se instaura nos processos de ensinoaprendizagem. Nesse contexto, é vista como uma estratégia que possibilita a reflexão a respeito dos caminhos percorridos, tendo como parâmetro os objetivos definidos, as metas estabelecidas, as competências e habilidades desejadas na formação profissional. A discussão sobre a temática está 
vinculada a aspectos teóricos e metodológicos que visam contribuir para a reflexão sobre a experiência no campo da Educação a Distância que utiliza como mediadora da ação didático-pedagógica uma plataforma de aprendizagem repleta de recursos instrumentais que favorece a implementação de uma avaliação processual, na medida em que permite a interlocução entre sujeitos, possibilita o acompanhamento dos alunos em momentos síncronos e assíncronos e contribui para a construção individual e coletiva do conhecimento.

A utilização ampliada do meio técnico-informacional provoca "ruídos" que devem ser escutados pelos sujeitos como se fossem dispositivos que atuam simultaneamente, diminuindo o nível de resistência para o qual todos são atraídos e aumentando o repertório de possibilidades de mudanças do campo de atuação do mesmo sujeito. A Educação a Distância se incorpora como uma abertura que possibilita a inserção de novas tecnologias e estratégias educativas que retroalimentam o sistema como um todo, navegando pelas ondas das incertezas e flutuações que regem os processos educativos. Mobilizar emergências cognitivas capazes de enredar estratégias e discursos que favorecem a aprendizagem como um caminho que se trilha entre rosas e espinhos é um desafio a ser perseguido, sem a certeza de que seremos bem-sucedidos.

Se a avaliação é um caminho a ser percorrido objetivando verificar os movimentos que moldam e regulam a aprendizagem, saber utilizar esse dispositivo é adentrar na trama movente, flutuante e incerta que rege a cognição. Dizer que alguém aprendeu ou não aprendeu determinado conteúdo se constitui o drama que enreda parte da práxis docente. Isso porque a avaliação, por um lado, está cercada de instrumentos que, mesmos sendo flexíveis e abertos, visam, em certa medida, ser o testemunho do que foi visto, lido, ouvido, demonstrado, verificado, buscando a coerência, a coesão, a disciplina, a área, a linguagem. Por outro, atestar e revelar que houve aprendizagem se constitui percorrer um caminho feito de curvas sinuosas e retas, terrenos planos e escarpados, desfiladeiros e sopés em que o testemunho é sempre uma afirmação parcial condicionada ao caminho que foi percorrido. O "aprendiz" adquire competências e desenvolve habilidades que são verificadas por processos avaliativos, reflexo da sua trajetória e dos diferentes níveis de interação que compõem o processo formativo.

Nesse caminho incerto que envolve o ambiente da aprendizagem, a avaliação é um elemento inseparável. Com ela emergem questões como prova, nota, norma, regra, medida, conceito, disciplina, excelência, regulação... como que por ironia, a avaliação não é bem avaliada pelos indivíduos. A abordagem desse tema traz à tona imagens, ideias e equívocos que podem despertar satisfação em exercitá-la ou provocar medo, angústia, dor, incerteza. Exemplos que expressam as sensações anteriormente enumeradas são abundantes e podem estar longe e perto de qualquer um, sejamos nós avaliadores ou avaliados dentro desse processo.

Recorra à sua memória. Lembre-se de momentos em que você foi submetido à avaliação e como se sentiu em cada um deles. No seu elenco de fatos relembrados, qual o perfil que a avaliação assume? Quais as imagens preponderantes? Quais foram as contribuições que essas avaliações tiveram dentro do processo de ensino-aprendizagem?

É possível que, no seu exercício, tenham surgido imagens relacionadas a dragões ou coelhos, serpentes ou joaninhas, túneis escuros e iluminados, ruas sem saída e/ou de mão dupla, carrascos, juízes, professores... essas imagens podem estar acompanhadas da sensação de fracasso, insuficiência, prejuízo, surpresa, incapacidade, desestímulo, ou pela sensação de certeza, reflexão, alegria e conquista... muito bem, envolvida por tais termos/imagens/sensações, a avaliação faz parte da vida das pessoas e se prolifera em um terreno fertilizado por ambiguidades.

No decorrer do tempo, essa variável passa a ser formalizada em um campo do saber e das práticas pedagógicas que extrapola a vivência cotidiana das pessoas e se instaura em ambientes que assumem a tarefa de exercitá-la como premissa para a progressão, inserção e trabalho, sendo um campo específico de atuação, reflexão e ação social. Nesse sentido, ocupa um lugar na dinâmica cultural, seja em sua função instrucional ou não. $\mathrm{O}$ ambiente educacional, em suas diferentes dimensões, talvez seja o lugar em que essa variável se instaure e tenha maior visibilidade na estrutura social. 
Nos últimos anos tem havido importantes mudanças no cenário brasileiro quanto às discussões e ações que versam sobre a avaliação. Há, de forma geral, um sentimento de que é necessário repensar os processos avaliativos no intuito de criar modelos e instrumentos que melhorem, cada vez mais, o sistema, diminuindo o grau de "perversidade" inerente a ele. Isso porque avaliar competências e habilidades tem sempre uma consequência imediata, que é identificar e escolher, entre muitos, aqueles que podem fazer parte do sistema e também evidenciar os excluídos dele. Essa parece ser uma condição da qual não podemos nos livrar. No entanto, é possível fazer com que essa avaliação, de certo modo subjetiva, tenha critérios de análise claros e adequados à cada realidade.

Etimologicamente, avaliar vem do latim a-valere, que significa dar valor, emitir julgamento de valor. Seguindo a trilha da etimologia da palavra, podemos perceber que avaliar se institui como uma condição da e para a ação humana. Talvez aí resida uma das especificidades do humano: a capacidade de parar e refletir sobre um feito, atribuindo uma conotação de valor. Quando avaliamos, temos a intenção de adjetivar as atitudes, qualificando-as em ótimas, boas, regulares, insuficientes, belas, feias... de modo genérico, a avaliação ocorre cotidianamente a partir de critérios que estão no âmbito de uma valoração e julgamento definidos que praticamos sem, no entanto, refletirmos profundamente sobre ele.

Se a avaliação envolve uma valoração subjetiva, no âmbito do processo do ensino-aprendizagem, o julgamento de valor pode ser realizado longe de uma reflexão e definição de parâmetros? Como se definem os critérios balizadores dos processos avaliativos? Existe uma concepção específica para avaliação de ensino-aprendizagem quando trabalhamos na modalidade a distância?

Para responder a essas questões, é necessário ter um pressuposto que guie o sujeito na sua açãoreflexão avaliativa. Nesse sentido, é preciso perguntar: como se constrói um julgamento de valor? O que é a avaliação? Para que ela serve? Como se avalia? A resposta para esses questionamentos supõe definir o que é avaliação.

Podemos pensar que, no processo educativo, a avaliação não se define a partir da modalidade em que está sendo viabilizada, se presencial, semipresencial ou a distância. O sentido da avaliação deve ser entendido como um percurso ou caminho pontilhado por reflexões e ações que o aluno e o professor devem realizar guiados por um conjunto de mediadores, sejam estes de natureza teórica, prática ou teórico-prática. De modo abrangente, está presente nos mecanismos que possibilitam a oferta das atividades que regem o processo formativo em um sistema educacional e, de maneira específica, está no registro ou ficha de anotações sobre os alunos, que cumpre uma formalidade legal e quantifica, de modo objetivo, a aprendizagem.

Avaliar é percorrer um caminho; é tropeçar em obstáculos; deparar-se com as incertezas; é encontrar as possibilidades e os limites que se apresentam no processo da aprendizagem. Assim, a avaliação pode ser entendida como experimentação teórica ou prática do sujeito com a matéria objeto da aprendizagem. É com a manipulação da matéria que ele pode se deparar com as suas potencialidades, seus limites e suas superações. Estimulados pela experimentação, o professor e o aluno podem trilhar as veredas com paradas, abertura de novas trilhas, reorganizações nos trajetos percorridos. Assim, pensar sobre a avaliação no processo de ensino-aprendizagem requer problematizar questões que envolvem a prática pedagógica docente, as matrizes teóricas que a fundamentam, os tipos de avaliação e as estratégias utilizadas.

Ao professor cabe, através do processo de ensino-aprendizagem, construir uma proposta avaliativa atrelada às competências e habilidades que são necessárias à formação do aluno. É importante que o docente saiba definir as matrizes de competências que envolvem uma área de conhecimento e como esta pode se constituir no campo de experimentação do aluno. Trata-se de considerar o conteúdo como a argamassa que o aluno tem que manusear para poder se apropriar e aplicar em situações específicas. $O$ conhecimento disciplinar deve servir para tornar a compreensão mais crítica e reflexiva do cotidiano. O desafio do educador está em construir, no campo disciplinar, as estratégias de experimentação sem cair na banalização do cotidiano que tudo justifica, nem na arrogância do conhecimento que tudo explica. A avaliação, nessa perspectiva, pode se constituir na força que liga um 
campo ao outro, sendo o estímulo que impulsiona, no processo formativo, as combinações necessárias entre competências, habilidade e resultados.

\section{COMPETÊNCIAS E HABILIDADES}

Mas que competências e habilidades são essas? Todo professor pensa sobre isso quando elabora o seu planejamento didático?

É possível que o docente pense nas competências relacionando-as diretamente à disciplina que leciona, procurando verificar os objetivos gerais e específicos que foram traçados. Essa é uma das faces à qual a competência está associada. Porém, alguns autores estão ampliando essa discussão, mostrando que a definição de competências envolve algo além dos conteúdos disciplinares. Nilson José Machado, no artigo Sobre a idéia de competência (2002), reflete nessa direção. Segundo ele, a organização do conhecimento está pautada em objetivos disciplinares que garantam uma formação profissional e, como decorrência, uma formação pessoal. Essa lógica alicerça a organização curricular de modo que, excessivamente, abordam-se disciplinas e matérias em detrimento de temas ou conjunto de temas.

Continuando na direção do que o referido autor defende, paira sobre essa discussão uma dicotomia entre disciplina e competência. Porém, deve-se descartar essa perspectiva, pois não há como separar a definição de competências daquilo que deve ser ensinado. Outro aspecto fundamental nessa discussão é: "como" esses componentes serão trabalhados? Nesse sentido, a questão é que há uma imbricação entre conteúdos e competências e a identificação destas reorganiza a estrutura disciplinar, bem como redesenha o mapa do conhecimento e, por consequência, o do aprendizado.

As competências visam responder à seguinte questão: ao finalizar um curso, do que um profissional é capaz? Complementando essa questão emerge uma outra, qual seja: como saberemos se o que foi ensinado foi apreendido? Assim, a resposta para essas questões torna indissociável a relação entre competências, habilidades, aprendizagem e avaliação. A organização do saber-fazer pedagógico em uma disciplina, independentemente da modalidade para a qual está sendo ofertada, está atrelada às estratégias que possibilitam o acompanhamento da aprendizagem, sendo a referência que permite entender os obstáculos, os erros e os acertos existentes no processo. As competências devem estimular a organização do conteúdo e a ação dos sujeitos na direção de um trabalho colaborativo, articulado e em sintonia com os contextos socioculturais existentes.

Se as competências estão no âmbito de uma proposição ampla, as habilidades são as diversas formas encontradas para a realização ou concretização das competências definidas. Para que uma competência se concretize, é necessária a definição de múltiplas habilidades, de maneira que um mesmo conteúdo possa ser experimentado em diferentes situações, ou que um mesmo conteúdo possa ser visto sob diferentes perspectivas; assim, as possibilidades de aprendizagem são maiores. "É como se as habilidades fossem microcompetências, ou como se as competências fossem macro-habilidades" (MACHADO, 2002, p. 145).

Para Perrenoud (2002, p. 19), a competência é uma "aptidão para enfrentar uma família de situações análogas, mobilizando de uma forma correta, rápida, pertinente e criativa, múltiplos recursos cognitivos: saberes, capacidades, microcompetências, informações, valores, atitudes, esquemas de percepção, de avaliação e raciocínio".

Nessa direção, a definição de competências e habilidades está atrelada à área de conhecimento e à perspectiva que se aposta no processo de formação. Não se trata de algo novo, mas de uma estratégia que requer do professor um exercício de reflexão contextualizado, integrado e comprometido com a organização do conhecimento para atender à condução de uma aprendizagem significativa, cujo centro é o aluno e sua formação. Cabe ao professor, no seu planejamento, estabelecer os caminhos a serem percorridos de acordo com o que deseja ser alcançado pelo aluno. 
A avaliação se insere, portanto, no interior das competências e habilidades que são planejadas e implementadas pelo professor. Desta feita, não se constitui uma surpresa, nem uma elaboração distinta das estratégias que estão incorporadas ao processo de ensino. Ao professor cabe desenvolver um processo de "escuta", reflexão e ação que possibilite ampliar os processos de experimentação dos sujeitos com os saberes que são selecionados e que fazem parte da fundamentação teórica e prática da formação dos indivíduos. $\mathrm{O}$ aluno deve ser envolvido por estratégias que o façam se sentir seguro em trilhar os caminhos quanto aos resultados que vai alcançando ao longo do processo de ensino-aprendizagem. A avaliação do aluno feita pelo professor deve se somar à autoavaliação, que auxilia o estudante a tornar-se mais autônomo, responsável, crítico, capaz de desenvolver sua independência intelectual.

Para Hoffmann (2002, p. 17), a avaliação deve ser vista em uma perspectiva investigativa e questionadora, que fundamenta a prática educativa. Para a autora, "a avaliação é reflexão transformada em ação", devendo ser considerada uma estratégia interativa entre professor e aluno, capaz de dinamizar o processo de organização e aquisição do conhecimento.

Assim, deve-se desenhar um processo contínuo de avaliação que estabeleça um juízo de valor crítico quanto às práticas educacionais dos professores; à escolha dos materiais a serem utilizados; às competências a serem estimuladas; às habilidades a serem desenvolvidas. Essas escolhas tornam-se a base que subjaz o próprio processo de ensino-aprendizagem, que se realiza próximo das visões que veem como momentos articulados os processos educativos daqueles que envolvem os avaliativos.

\section{AVALIAÇÃO NA EaD: DESENHANDO POSSIBILIDADES}

Se temos por premissa que a aprendizagem deve ocorrer por definição de competências e habilidades; se entendemos que o processo de ensino-aprendizagem está atrelado ao processo avaliativo; se concebemos que a avaliação é, por um lado, testemunho, mas por outro é um caminho aberto em que o professor deve estimular a formação autônoma do sujeito aprendiz, cabe refletir agora sobre algumas estratégias que seriam pertinentes e que possam servir como parâmetro para auxiliar a ação docente, desenhando possibilidades de avaliação na EaD.

A modalidade de Ensino a Distância se desenvolve fazendo uso de um conjunto de ferramentas didáticas que são utilizadas como mediação no processo que envolve o ensino. Para o professor e para o aluno essas ferramentas se constituem meios relevantes, porém, em muitos casos, são ainda "tesouros a descobrir". Em uma sociedade cada vez mais edificada nas teias das infovias, que são capazes de armazenar, processar e distribuir uma quantidade cada vez mais robusta de informações, prospera uma abundância de recursos que derivam das múltiplas possibilidades de uso dessas informações. Nesse sentido, é perceptível que a produção ocorre em uma escala exponencial, enquanto que o uso dos meios se dá em escalas menores. Essa relação entre a produção e o uso dos meios se insere no contexto educativo, impondo-se como um elemento primordial que norteia as ações e está na base do processo avaliativo.

Está em curso a organização de um campo instrucional e de formação de uma mentalidade que se fundamenta na formulação e na utilização dos meios que veiculam, alimentam e retroalimentam as demandas desse "novo mundo". A afirmação de Gardner (2007, p. 18) a respeito do velho e do novo na Educação suscita a reflexão sobre em que se deve apostar se a Educação quiser aproximar-se do ritmo da sociedade informacional e tecnológica atual. Para esse autor, "a capacidade de pesquisar em corpus de informação enormes, impressos e eletrônicos, e de organizar essa informação de maneira útil é mais importante do que nunca" (GARDNER, 2007, p. 19).

Nessa direção, como avaliar a aprendizagem dos alunos em um contexto de abundância de informações de rápido acesso? O conteúdo está no livro didático veiculado em suporte de papel, mas também armazenado nas infovias, que distribuem as informações em tempo real. $O$ aluno pode ter acesso às informações sem necessariamente se deslocar do seu quarto, basta que tenha um computador plugado à rede mundial de computadores. Ele dispõe não só desses registros, mas também de grupos que podem 
compartilhar, discutir e refletir sobre essas mesmas informações. Nesse cenário, é necessário questionar a respeito do que se impõe quando colocamos na balança a produção da informação e o seu uso pela sociedade. De modo emblemático, é perceptível que os "bytes" que processam e são responsáveis pelo alicerce do processo educativo ficam em desvantagem quando comparados àqueles que estão na base do processo produtivo.

Essa constatação é um problema e um componente importante para alimentar a ação educativa. Enquanto problema revela-se como insolúvel, pois o ritmo da aprendizagem é mais lento, requerendo processos cognitivos complexos de reconhecimento, compreensão, apropriação, subjetivação e significação. Enquanto componente que alimenta a ação educativa, apresenta-se como um desejo a ser alcançado e, nesse aspecto, motiva o ser e o fazer daqueles que estão envolvidos no processo. Na mesma medida, essas duas condições alimentam a dialógica entre a inovação e a permanência das práticas no contexto educacional.

Desta feita, o exercício cotidiano que se instaura no campo educativo está em saber selecionar o que se constitui fundamental à formação, definido as diretrizes que orientam o percurso metodológico a ser seguido, levando em consideração as ferramentas digitais e virtuais disponíveis. Nesse contexto, a correlação entre aprender e ensinar se sustenta nos pilares informacionais que dão consistência à convivência de sujeitos em um ambiente cada vez mais articulado e desafiador. A Educação deve ser capaz de propiciar meios, orientações e caminhos que podem ser trilhados pelos aprendizes, levando-os a usar, em contextos distintos, uma informação, o que requer a capacidade de saber tomar decisões, recriar saídas, religar componentes e agir, reconhecendo, considerando e respeitando as diferenças e os limites dos grupos sociais.

O desafio didático é abrigar os meios informacionais em contextos educativos que levem à interação entre os sujeitos e o conhecimento, produzindo um ambiente favorável à aprendizagem daquilo que é fundamental em uma sociedade que se modifica constantemente. O saber-fazer está atrelado à "fabricação" de uma convivência que ocorre por mediações. Entre o sujeito que aprende e aquele que coordena o processo de aprendizagem se instaura um conjunto de mediações que são responsáveis por estabelecer pontes que ligam, articulam e penetram as artérias que irrigam e dão vitalidade ao sistema. A Educação a Distância, ou a educação virtual, supõe a utilização de tais meios como estratégicos do processo didático e estes devem ser considerados nos processos avaliativos.

\section{AVALIAÇÃO E OS AMBIENTES VIRTUAIS DE APREDIZAGEM (AVA)}

Destaca-se, nessas mediações, o ambiente de aprendizagem moodle. Podemos perguntar não pelas ferramentas que essa plataforma dispõe e que servem para elaborar instrumentos de avaliação para os alunos, como o questionário on-line, a organização de tarefas, os fóruns, entre outros, mas sim pela concepção que rege o funcionamento de um AVA. De modo sintético, podemos dizer que esses ambientes favorecem a organização de cenários colaborativos, em que a comunicação em rede se estabelece e se propaga inserindo uma comunidade de iniciados ou de iniciantes. Na mesma medida, temos que o funcionamento desses ambientes é eficaz quando os indivíduos assumem a sua autonomia e imprimem as suas marcas, registrando, provocando e demonstrando as suas impressões, dúvidas, convicções, saberes, possibilitando a interlocução e construção de um conhecimento em rede. Percebe-se que os AVA como ambientes de aprendizagem caminham no terreno ambíguo do grupo e da individualidade, da colaboração e da autonomia, da participação e da mediação.

A sugestão de Lévy sobre a aprendizagem e o uso das tecnologias favorece a problematização abordada, quando ele afirma:

Aprendizagens permanentes e personalizadas através de navegação, orientação dos estudantes em um espaço do saber flutuante e destotalizado, aprendizagens 
cooperativas, inteligência coletiva no centro das comunidades virtuais, desregulamentação parcial das competências em tempo real [...] esses processos sociais atualizam a nossa relação com o saber (1999, p. 177).

$\mathrm{Na} \mathrm{EaD}$, o estímulo à aprendizagem colaborativa, a navegação hipertextual, a orientação em um espaço flexível colocam em xeque as formas convencionais de ensinar e aprender que utilizam ambientes fixos, saberes rígidos e práticas repetitivas. Os AVA podem favorecer um deslocamento na medida em que permitem o compartilhamento de ideias e o acompanhamento do aluno em diferentes situações e temporalidades. No entanto, esses ambientes ainda apresentam ambiguidades quando analisamos o seu uso relacionado ao contexto formativo. Persiste uma indefinição pedagógica e insegurança quanto à sua eficácia.

Para auxiliar nessa discussão, vamos tomar como exemplo os fóruns que são abertos nas disciplinas para servirem de comunicação entre alunos, professores e monitores. Esta é uma ferramenta de interação assíncrona, mas que objetiva uma participação ativa, estimulada pelo diálogo. Analisando o funcionamento desse recurso, pode-se destacar que a participação dos alunos tende a priorizar a interação com o professor mais do que com os próprios alunos. Verifica-se que ainda prevalece a visão de que o discente aprende a partir daquilo que o docente ensina. Assim, há uma recorrência por perguntas, mais do que por afirmações e pontos de vista sobre os conteúdos estudados.

De modo geral, a intervenção do aluno no fórum é muito baixa e está muito voltada à solicitação de respostas visando obter informações precisas sobre os conteúdos abordados em provas, datas para entrega de trabalhos, dúvidas sobre uso do ambiente. Um exemplo são as perguntas referentes a uma determinada atividade avaliativa que está prestes a fechar seu período de postagem. Há muitos casos em que a informação já veiculada passa a ser repetida, pois o sujeito procura obter uma resposta individual quando o ambiente favorece o uso coletivo. Verifica-se que as redundâncias evidenciam as contradições entre estrutura informacional e usuário. Isso porque, embora o ambiente esteja preparado para uma comunicação em rede ou rizomática, com quebra de hierarquias e projeção de múltiplas possibilidades de conexões e interações, os sujeitos que utilizam as ferramentas operam em um modelo cognitivo verticalizado, com estruturas ainda rígidas e lineares.

É importante refletir sobre o fato de que, embora estejamos em um mundo informacional e tecnológico, com ampliação das possibilidades de aprendizagem e avaliação, ainda estamos vivenciando um processo desigual entre o que é possível utilizar, a forma como utilizamos e o que efetivamente temos competência para manusear. A sociedade digital que está em curso tem provocado alterações significativas na forma de produzir e disponibilizar conhecimento, mas ainda enfrenta dificuldades técnicas, teóricas e práticas. Isso, no entanto, não diminui o desejo e o exercício que vêm se firmando no âmbito de uma Educação mais rizomática ou de uma organização do conhecimento em árvore, como sugerido por Lévy, em que

cada membro de uma comunidade pode fazer com que toda a diversidade de suas competências seja reconhecida, mesmo as que não foram validadas pelos sistemas escolares e universitários. [...] Trata-se de um mapa dinâmico, consultável na tela, que possui de fato o aspecto de uma árvore, e cada comunidade faz crescer uma árvore de forma diferente (1999, p. 177).

As estratégias de ensino estão tateando o uso desse modelo, mesmo considerando a modalidade a distância. Ainda é perceptível o estimulo a fórmulas que reduzem a capacidade de sinergia entre a informatização e os fazeres pedagógicos, retardando o avanço de bases cognitivas na utilização de modelos com perfis de redes, rizomas ou árvores. 
Outra questão que deve ser refletida é que o fórum não está desenhado para atender de modo objetivo a finalidade de uma aprendizagem que se realiza sem hierarquias ou pré-requisitos. $O$ modelo de postagem das informações assume um contorno vertical, sem a possibilidade de ramificações ou sínteses mais integradoras dos conteúdos. As postagens ficam disponíveis e podem ser acessíveis a todos os integrantes do grupo, mas a reorganização depende de quem as utiliza e, mais, depende da concepção de quem está conduzindo o processo. Caso se conceba que a informação deve ser utilizada por todos, devese considerar que os participantes têm acesso à informação, colocando em evidência os diferentes uso e possibilidades de ampliação de uma mesma informação. Em sentido contrário, limita-se o uso e o fluxo de informações quando se restringe o acesso por grupo ou pessoas, visando atender finalidades específicas. Em ambos os casos, é perceptível que o aluno age de modo bastante objetivo ao credenciar como seu interlocutor o professor, e não o seu colega. Com raras exceções, verifica-se um diálogo que envolve os conteúdos da área entre os alunos. A maioria prefere estabelecer esse vínculo com o professor, perguntando mais do que opinando. Assim, o professor/monitor assume um papel fundamental nesse processo, que é o de saber coordenar a participação, estimulando a interação entre os alunos, a produção de redes e conexões entre as informações; construindo a elaboração de sínteses abertas que favoreçam a projeção de outras ramificações e articulações.

Nesse sentido, estamos trilhando um caminho em que temos consciência da existência de um tesouro a ser descoberto. A cada passo dado na direção desse tesouro, desvendamos uma peça e a incorporamos ao processo, o que não garante utilizá-la em sua plenitude. Nesse sentido, vivencia-se um dos pilares da Educação do futuro, que é "aprender a aprender". Na medida em que usamos, aprendemos e reorientamos as nossas práticas. Percebe-se que a teoria se realiza na prática, a prática está consubstanciada em uma teoria ainda nascente e por fazer. Dentro desse contexto, não é somente o aluno que aprende a desvendar quão complexo é esse processo. O professor/monitor é um agente fundamental no processo de aprender a ensinar quando falamos de AVA.

O Ensino a Distância se constitui num berçário para a confecção de uma teoria da informação e da comunicação pautada por processos de mediação de aprendizagem. Dessa maneira, é preciso aprender com os ambientes como desenvolver as competências e habilidades necessárias à formação do sujeito. É preciso criar estratégias de interação que estimulem o aluno a participar dos ambientes colaborativos, organizando a sua aprendizagem. Nesse sentido, o professor tem papel importante, pois cabe a ele direcionar os passos, estabelecer as estratégias, indicar os caminhos.

Utilizar os AVA como ambiente de avaliação é transformar esse ambiente colaborativo em um operador das aprendizagens. Nessa direção, é preciso que os sujeitos se apropriem e ajam fomentando práticas que corroborem as potencialidades que os meios oferecem. Os AVA devem ser vistos e utilizados longe dos controles e próximos da criatividade. Assim, cabe uma reforma na condução das práticas educativas do professor e do aluno, os quais devem empreender esforços na direção de transformar a participação em interação de modo que o aluno seja capaz de organizar o seu caminho de aprendizagem, guiado por orientações e materiais que favorecem trilhar esse percurso. Ao professor cabe ser um facilitador de tal percurso, disponibilizando as ferramentas, estruturando estratégias, acompanhando o desempenho, retificando rotas, coordenando discussões específicas das áreas de conhecimento.

A avaliação deve se estabelecer no processo de implementação das ações e dos instrumentos, levando o aluno a reconhecer em que nível se encontra no grupo e individualmente. Portanto, na EaD, a comunicação síncrona é complementar à comunicação assíncrona. É nesta que o volume de informações é mais abundante e detalhado, dando possibilidades ao professor de perceber os ritmos de apropriação do conhecimento pelo diferentes sujeitos ou, como sugere Lévy (1999, p. 173), aprender a manusear um "saber-fluxo caótico, de curso dificilmente previsível no qual se deve agora aprender a navegar".

\section{AVALIAR POR ESTRATÉGIAS NA EaD}


A apropriação do conhecimento em um "saber-fluxo caótico" nos remete a considerar a avaliação por meio de estratégias. A existência das estratégias depende de ações que são desenvolvidas na esfera dos sujeitos. Assim, de nada vale pensar em estratégias se as pessoas não estiverem dispostas a agir utilizando informações que sirvam para alimentar os processos de organização da aprendizagem.

O sentido da avaliação está em informar sobre redundâncias e ruídos que se constituem em códigos que precisam ser decodificados. É a revelação parcial de uma organização cognitiva de dados que foram subjetivados e reprocessados a partir de mecanismos estruturais, em que pesam as condições individuais e coletivas nas quais os alunos estão envolvidos. Nessa perspectiva, a avaliação está organizada e se viabiliza para concretizar concepções que podem estar no nível do programa ou da estratégia. Para Morin (2005, p. 250/251), o conhecimento é programa e estratégia. Mas o que seriam essas duas noções e como podem servir para auxiliar uma reflexão sobre a avaliação?

Primeiro, vejamos o que esse autor diz sobre o que é o programa. Para Morin (2005), a nossa organização cerebral funciona a partir de estruturas e patterns, base rígida que assimila, codifica, decodifica e propicia as possibilidades de sinapses organizadoras do conhecimento. É fundamental que essa base rígida seja alimentada por informações que diversifiquem as competências, favorecendo uma ampliação das possibilidades de combinações sinápticas que complexificam, enriquecem a construção da realidade fenomênica.

Nesse sentido, o programa "é um conjunto de instruções codificadas que, quando aparecem as condições específicas de sua execução, permitem o desencadeamento, o controle, o comando por um aparelho seqüencial de operações definidas e coordenadas para alcançar certo resultado" (MORIN, 2005, p. 250). O programa opera a partir do que está informado previamente, sendo vinculado a processos executivos. Pensar sobre essa perspectiva é criar uma base de informações fixas que alimentam o sistema, procurando respostas que permitam organizações, visando atender aquilo que já está estabelecido. No âmbito da avaliação, poderíamos supor que uma visão programática requer estabelecer objetivos precisos e segui-los, procurando sempre verificar se eles estão sendo atendidos. Os desvios, ruídos e frustrações devem ser observados para que sejam feitas interferências, colocando novamente no eixo aquilo que tende a desequilibrar ou pôr em risco o que foi pretendido.

E a estratégia? A estratégia comporta, assim como o programa, segundo Morin, o desencadeamento de sequências de operações coordenadas. Porém, diferentemente do programa, a estratégia não está baseada apenas em decisões iniciais, mas naquilo que se apresenta no processo, estando atenta aos acontecimentos, eventos, ruídos e desvios que aparecem. A estratégia se desconstrói, submete-se a riscos. Nesse sentido, a estratégia "supõe a aptidão para empreender uma ação na incerteza e para integrar a incerteza na conduta da ação. Significa que a estratégia necessita de competência e de iniciativa" (MORIN, 2005, p. 250).

Agora, cabe perguntar: como as noções de programa e estratégia podem ser aplicadas aos processos avaliativos de modo complementar? Se temos por premissa que avaliar serve para encontrar as possibilidades e brechas nos processos de aprendizagem, podemos articular essa duas noções visando complexificar as condições de avaliação e autoavaliação que envolvem alunos e professores.

O programa é importante para proporcionar ao professor e aos alunos as diretrizes iniciais sobre as quais os processos de aprendizagem estão alicerçados, bem como as matrizes que serão implementadas nos processos avaliativos. Essas condições iniciais orientam as ações, mas não se constituem num fim em si mesmas.

A estratégia é fundamental para possibilitar ao professor incorporar, à sua ação, o risco, os desvios, os ruídos, os desafios e erros que se apresentam no decorrer do processo, tornando a avaliação uma estrutura aberta. Nesse sentido, amplia a base estrutural sobre a qual se fundamenta a atividade disciplinar. Trata-se de fornecer elementos que favorecem novas sinapses cognitivas, assumindo o acontecimento e o evento como estruturantes dos processos de aprendizagem. 
Desse modo, programa e estratégia recorrem um ao outro. No entanto, a riqueza da estratégia no processo avaliativo é assumir sem culpas ou medos a tomada de decisão em situações de incerteza. A estratégia no seio da avaliação significa encontrar caminhos diante de situações inesperadas. O professor convive sempre com o inesperado e, muitas vezes, pensa que deve desconsiderá-lo, mantendo aquilo que está estabelecido no programa, pois se sente inseguro diante do que não domina, ou seja, as incertezas. Então, precisamos aprender a lidar com a incerteza e a novidade, incorporando-as ao processo de aprendizagem e ao avaliativo. A estratégia não é um meio de ação, mas é a "arte da ação viva". Assim, ela é parte importante dentro do desenvolvimento e aprimoramento da avaliação e, por consequência, contribui com a aprendizagem.

Em EaD, mais do que em outra modalidade, a articulação entre programa e estratégia deve ser estimulada. Sabe-se que nessa modalidade há uma certa rigidez programática, visando orientar os sujeitos no desenvolvimento de suas ações para que eles não se percam. No entanto, esse mesmo campo é o locus de produção de desvios, de ruídos, o que requer pensar por estratégias no processo avaliativo. Assim, essa sugestão se apresenta como desafio, pois acreditamos que necessita de uma aprendizagem no âmbito formativo, principalmente na esfera docente.

Para finalizar, perguntamos: que tipos de estratégias são desafiadores em uma sociedade cada vez mais organizada a partir da dependência de modelos computacionais e em rede? Que tipo de estratégias você considera relevante para estimular o desenvolvimento de competências em um discente de EaD? Você consegue articular essas competências no processo de formação e avaliação do aluno que está inserido em EaD? Como? Tente refletir sobre essas questões e veja em que desafio você está inserido. 0 desafio é uma das qualidades inerentes ao ofício de ser professor. Para além da perspectiva que institui o desafio como momento a ser superado, assume-se a ideia de que este é perene no processo que envolve a formação em diferentes escalas, sendo o estímulo para reorganizar as práticas, reavaliar as competências e refazer itinerários avaliativos.

\section{REFERÊNCIAS}

HOFFMANN, J. Avaliação: mito e desafio: uma perspectiva construtivista. 31. ed. Porto Alegre: Mediação, 2001.

HOWARD, G. Cinco mentes para o futuro. Porto Alegre: Artmed, 2007.

JACQUES, D. A educação para o século XXI: questões e perspectivas. Porto Alegre: Artmed, 2005.

LÉVY, P. Cibercultura. São Paulo: ed. 34, 1999.

MACEDO, L. de. Situação-problema: forma e recurso de avaliação, desenvolvimento de competências e aprendizagem escolar. In: PERRENOUD, P.; THURLER, M. G. As competências para ensinar no século XXI: a formação dos professores e o desafio da avaliação. Porto Alegre: Artmed, 2002.

MACHADO, N. J. Sobre a idéia de competência. PERRENOUD, P.; THURLER, M. G. As competências para ensinar no século XXI: a formação dos professores e o desafio da avaliação. Porto Alegre: Artmed, 2002.

MORIN, E. A cabeça bem-feita: repensar a reforma, reformar o pensamento. Rio de Janeiro: Bertrand Brasil, 2000.

2002.

Os sete saberes necessários à educação do futuro. 6. ed. São Paulo: Cortez; Brasília: UNESCO, 
O método 2. A vida da vida. Porto Alegre: Sulina, 2005.

PERRENOUD, P. Avaliação: da excelência à regulação das aprendizagens - entre duas lógicas. Porto Alegre: Artmed, 1999.

PERRENOUD, P.; THURLER, M. G. As competências para ensinar no século XXI: a formação dos professores e o desafio da avaliação. Porto Alegre: Artmed, 2002. 